\title{
THE PROCEDURAL AND NORMATIVE OVERSIGHTS WHEN DOING A SURVEY REPORT. THE MEDICAL-LEGAL EXPERTISE VERSUS JUDICIAL SURVEY IN MEDICINE
}

\section{A. M. Chipurici}

\author{
Adrian-Marius Chipurici \\ Law and Economics Faculty, Social Sciences Department, \\ Agora University of Oradea, Oradea, Romania \\ *Correspondence: Adrian Marius Chipurici, Agora University of Oradea, \\ 8 Piaţa Tineretului St., Oradea, Romania \\ E-mail: mchipurici@gmail.com
}

\section{Abstract}

The study attempts to present an abnormality in the Romanian system of expertise.

I will pass in review the normative documents that regulate the medical-legal expert's activity and those that organize the activity of the judicial expert in medicine, ascertaining a different way of approaching the two kinds of expertise, especially the criminal one, by the bodies with judicial responsibilities. In the end, there are solutions advanced with a view to normalizing the situation.

Key words: expertise, medical-legal expert, medical judicial expert.

\section{Introduction}

Presently, the medical-legal survey is relative to the judicial bodies' activity which, thus, draws on the knowledge acquired by certain specialists within the evidence process, the medical-legal expertise being an important means of probation.

The activity of the medical-legal services in Romania, is regulated by Government Ordinance no. 1/2000 including all the subsequent amendments and additions, being bound to carry out the surveys in the terms of article no. 117 CPP (Criminal Procedure Code, that is in first degree murder, psychiatric expertise and when the necropsy had not been carried out although it was necessary. The activity of judicial technical expert in the specialties of pharmacology-medicine-dentistry is regulated by the provisions of Romaniain Government Ordinance no. 2/2000 including all the subsequent amendments and additions.

Regarding the legislative situation anterior to the Decision of the Romanian Constitutional Court no. 143 of $5^{\text {th }}$ of October, 1999, we mention that according to article no. 120, paragraph (5) of the Criminal Procedure Code, the parties did not have the possibility to ask the designation of a recommended expert, who would participate in the development of expertise activities if the latter is carried out by a medical-legal institute, by a criminal expertise laboratory or any other specialty institute. Practically, in this situation, the criminal prosecution body or the court of law would address these institutions with a request for expertise, without giving the opportunity to the involved or regarded parties to designate in their turn another expert to participate to the expertise development. By the Decision no. 143 of $5^{\text {th }}$ of October, 1999, the Romanian Constitutional Court actuated that "the provisions of the article no. 120, paragraph 5 of the Criminal Procedure Code contravene to the provisions of article no. 24, paragraph (1) of Constitution, which guarantees the right to defense". In the opinion of the Court, not giving to the parties involved in a criminal process the right to 
request for an expert recommended by them to participate to the expertise development when this is about to be carried out by a specialized institution according to the law, unaccountably restricts their right to defense.

Hereinafter, the Romanian Constitutional Court has ascertained that if the expert recommended by the interested party does not participate to the expertise development, the nonparticipation cannot be corrected by its right to request ulterior explanations on the expertise report or filling in the incomplete expertise or carrying out new expertise when, due to the position taken by the party, the judicial body estimates that the expertise was not carried out professionally and correctly. The Court has determined that "the provisions of the article 120, paragraph 5 in the Criminal Procedure Code are unconstitutional because they specify that the provisions of the paragraphs 3 and 4, referring to the right of the parties to ask the appointment and an expert each recommended by them, who would participate to the expertise development, is not applicable in the situation of the expertise specified in article 119 , paragraph 2 , and the parties will have this right in all situations, disregarding the place where the expertise would be carried out".

In this context, we have to mention the fact that the article 119 of Criminal Procedure Code regulates the official experts' situation and have to view it in correlation with the whole "X Section - Expertise". It enumerates the surveys of expertise that, according to the law, are mandatory to be administered and who the official experts are, establishing within the article 120, paragraph 3 and 4 that the parties have the right to ask themselves the appointment of a recommended expert who would participate to the development of the expertise. If, by the time of the above mentioned decision of the Romanian Constitutional Court, these provisions were applicable to any other surveys of expertise except the medical-legal, criminal ones or those carried out by any specialized institute, after 1999, these provisions were applied disregarding the kind of expertise required in the criminal lawsuit.

To the same effect has the European Court of Human Rights advised, which in the case of Bonisch versus Austria, in the $6^{\text {th }}$ of May, 1985, had highlighted the fact that the lack of balanced treatment within the lower Court is the result of the inequity between the view of the expert suggested by the party and the official expert's view.

As a result of the Romanian Constitutional Court decision, the legislator took all the necessary measures and, beside the abolition of the provisions of article no. 120, paragraph (5) in the Criminal Procedure Code declared as unconstitutional, adopted a series of specific detailed settlements by which he organized the way in which the state authorities applied the dispositions through the Constitutional Court decision.

As a consequence, the following normative documents were modified and completed: 1. those in the article 28, paragraph 1 of Government Ordinance no. 1/2000 regarding the organization of the activity and operation of the legal medicine institutions, by which it has been stipulated that "the legal medicine institutions, with the service of a legal medicine Superior Council, elaborate lists comprising experts on different levels of competence, out of whom the interested parties can request, with payment, coroners or other specialists that would attend the designated official experts, according to the law, for certain medical-legal activities;

2. those in article 18 of Government Ordinance no. 2/2000 regarding organizing the activity of the judicial and extrajudicial technique expertise, by which it has been specified that "the interested party has the right to request that, beside the person designated as expert, another expert or specialist should participate in the future to the expertise development, at their expense, designated by the party, out of the category of people specified in the article 11-14"; 3. those in article 1, paragraph 2 of Government Ordinance no. 75 of $24^{\text {th }}$ of August 2000 regarding the criminal experts' authorization, by which it has been specified that "( 2$)$ in the development of the criminal expertise by the official experts, experts appointed by the judicial 
bodies can also participate, at the request of the parties and recommended by these, authorized in the terms of the present ordinance";

In this context, we stipulate the fact that the dispositions mentioned above were modified in such a way that, during the development of the criminal expertise by the official experts, experts designated by the judicial bodies can also participate, at the request of the parties and recommended by them. The problem is that, at the date of the Government Ordinance no. 2/2000 issuance, there were not judicial experts in medicine, for this reason the Romanian Constitutional Court decision should be updated because, after 2010 there were only 3 judicial experts in medicine, and presently there are 6 on the Ministry of Justice list.

There has to be mentioned that there are more inadvertences:

1. The expert in legal medicine is attested by the Ministry of Health Ordinance at the proposal of the Superior Council of legal medicine only out of the public sector (legal medicine services, legal medicine institutes, etc.), thus not existing any medical-legal expert independent of the state hierarchy;

2. The judicial expert in medicine sits an examination at the National Institute of Magistracy and is authorized by the Ministry of Justice in the whole medicine subject (the legal medicine is a subject that is studied in the sixth year at the University);

3. The legal medicine is not called Judicial Medicine anymore, but the judicial expert in medicine does not have in the criminal law any right in comparison to the medical-legal expert;

4. In the civil law, the judicial expert in medicine is recognized as official expert by the courts of justice;

5. According to the Government Ordinance no. 1/2000 regarding the organization and operation of legal medicine services with all the subsequent amendments and additions, the professors who teach legal medicine subject, who can be other than coroners in the higher education systems that are accredited and authorized, are rightful members in the Superior Council of legal medicine;

The present situation of developing the expertise in Romania and the problems the judicial system confronts with.

Out of the legislative framework applicable in civil matters, there can be observed that the Government Ordinances no. 1/2000 and no. 2/ 2000, with all the subsequent amendments and additions, create different conditions of operating the expertise in such a way that the medical-legal official experts would be visibly in a higher position compared to the ones recommended and requested by the parties or the judicial ones in medicine, in such a way that the situation in the expertise field in Romania has remained almost unchanged in the sense that developing the medical-legal expertise constitutes only the exclusive attribute of the legal medicine Services and the legal medicine Institutes, that are part of the public system, respectively the National Institute of Legal Medicine which is ancillary to the Ministry of Health.

This situation generated a series of critiques; some voices claimed that, in the field of the medical-legal expertise, with the exception of the cases provided by art. 117 of the criminal procedure code, there would be an exclusivity of the state, and this state of things would injure the defense right of the litigants who would lack the possibility to address to other entities (laboratories) in order to perform some independent judicial medical expertise.

Analyzing the above mentioned normative documents we consider that these findings are, in their ensemble, justified and pertinent, considering the fact that their related profile institutes and services function in Romania only in the public system. As a consequence, it can be observed that a change of the present situation can be accomplished only in a reform in the field of the medical legal expertise versus the medical juridical expertise that will take place at the level of the entire system, on the following coordinates: 
a) the possibility of performing the juridical medical-medical legal expertise by the universities, institutes, private laboratories also, together with those from the public system; b) the harmonization of the procedures applicable to the official medical legal experts, appointed by the juridical organizations, with those applicable to the juridical medical experts recommended by the parties;

The need of the reformation of the juridical expertise system in ensemble was underlined also in the project "The Consolidation of the Capacity of Juridical Expertise (MATO6/RM/8/2)" that took place in the period January - October 2007, under aegis of The Ministry of Justice from The Netherlands in partnership with The Ministry of Justice from Romania. The main recommendations formulated by the Dutch experts regarded:

- the fundamental reorganization of the system of juridical expertise and establishing it on new principles of organization and functioning;

- the unification and harmonizing of the procedures provided in the normative document regarding the juridical experts with normative documents that regularize the activity of the experts which can be recommended by the parties so that this last category could participate effectively in the technical activity of performing the medical legal expertise;

- the elimination of the state monopoly in performing the expertise, by establishing some mechanisms of evaluation and accreditation of some private medical legal/juridical institutes, that could perform their activity in this field this way, so exclusive up to the present;

Another problem observed in practice, whereby the juridical system is confronted, is the long period of time of the penal procedures. In this regard, it was observed that the large terms of performing the expertise could lead to the unjustified continuation of the penal trial period, with all the consequences that could come of this.

This aspect is valid also for the other categories of expertise. In conclusion, considering all the above mentioned aspects, we appreciate as being causes that lead to the delay of the trials the following:

1. the deficit of employees specialized on types of expertise from the public institutions and their related profile laboratories;

2. the lack of the harmonized procedures between the legislation applicable to the official medical legal experts and those recommended and chosen by the parties, aspects that stop the participation of the last professional category to the effective performing of the expertise, circumstance that could lead to many contestations, requests of clarification and performance of new expertise and counter expertise;

3. some litigants are interested directly of the delay of the juridical trial, intending the realization of the prescription terms, by repeated requests for the applications of the medical legal expertise to be admitted in the services of legal medicine, that have a period of solving relatively large, and the inducing, by repeated expertise and contrary points of view, of a state of confusion regarding the state of things inferred to the judgment. In the same time it can be observed that the acceptance of the opinion that the system doesn't have to be reformed, accepting the promoting of a simple policy of excessive supplementation of the number of experts for some specialties is not a solution due to the fact that;

4. some significant fluctuations could appear in the juridical system in the way that, depending on the economic and social criteria, some types of expertise can be directly influenced in the aspect of their dynamics and evolution;

5. from the technological point of view the medicine will register important progress each year and the implementation of some professional continuous training programs will be difficult to accomplish, on one side due to the fact that such programs will be expensive from the financial point of view and on the other side the experts will be excessively loaded with work, the terms of performing these works pressing them constantly, and they will not have 
the necessary time to be informed about the new authorized methods or procedures for their field of expertise;

6. the interdisciplinary character of medicine and its affinity with other field creates numerous difficulties when the juridical organizations have to individualize the problems that need to be solved by technical expertise in the medicine or by the medical legal expertise, both activities being different types of the juridical expertise;

Their elimination in order to normalize the situation presupposes, on the basis of our appreciations, the adopting of some complex measures in the plans of recovery which are well structured, and which can be made by initiating some real reforms on the level of the entire system of expertise from Romania.

In the absence of the global reform, the measures with matchlessly and inconsistent character would only have a temporary effect, the essential causes that determine the presented disfunctionalities cannot be eliminated.

\section{The necessity and the objectives of the reform}

Creating an adequate background where the activity of expertise in the private system could be performed, a background that could assure the quality of the works and respecting the deontological principles agreed on the level of European structures of juridical expertise.

The main means of reforming the system is the modification of the present regulation in the field, in the way of defining the notion of deregulation of the condition of performing the expertise, allowing the authorized independent experts to perform also medical legal expertise in the penal trial.

Also, by giving up the exclusivity of performing the expertise by official experts, it aims to assure all procedural guarantees for the parties from the penal trial, in the way that the juridical reports of expertise will offer a higher degree of objectivity.

\section{Conclusions}

\section{Precise measures of reform}

In order to accomplish the reform of the present system of medical expertise, in ensemble, it is necessary to take the following measures:

1. the liberalization of the activity of medical legal expertise by modifying the provisions of the Government Ordinance no. 1/2000, with the further modifications and additions, which regulates this activity in the present;

2. the recognition of the juridical expert in medicine and in the penal trials, as the official expert, by modifying the Government Ordinance no. 2/2000 with the subsequent modifications and additions;

3. founding some private laboratories of juridical medical and medical legal expertise where the experts could develop their activity, either as authorized individuals in individual laboratories, or as associates in laboratories founded as professional civil company with limited liability and juridical person;

4. establishing some conditions of authorizing the private laboratories of medical juridical and medical legal expertise;

5. assuring the independence of the private laboratories functioning in relation to the authorities, in the conditions when they are certified that they meet the International standards of quality by an accreditation organization recognized in the member states of the European Union;

6. establishing some conditions of validity of the expertise reports performed in the private system;

7. establishing some criteria and conditions that the experts should meet in order to be authorized, which would assure a guarantee of their competence and integrity; 


\section{A. M. Chipurici}

8. establishing a maximum limit of the taxes that would be perceived in the public system and in the private system so that the access of the citizens to this method of evidence would not be closed by prohibitive costs;

9. establishing some rights and obligations for the experts from the public system, that would assure their stability in this system avoiding their migration to the private system;

10. assuring a high level of professional training of the experts by including them in programs of continuous professional training and sanctioning those who do not participate to them.

\section{Bibliography}

A. Buzaianu, Judicial and Extrajudicial Technical Expertise, "Nomina Lex" Publishing House, Timişoara, 2010; 2009;

V. Iftenie, D. Dermengiu, Legal Medicine, C.H. Beck Publishing House, Bucharest,

Romanian Criminal Procedure Code;

Government Ordinance no.1/2000 with subsequent additions and modifications;

Government Ordinance no. 2/2000 with subsequent additions and modifications;

V. T. Dragomirescu, Medical-legal Problems and Methodology, "Medical" Publishing House, Bucharest, 1980. 